\title{
A PROTECTED LANDMARK MONUMENT: REINFORCEMENT, REHABILITATION, AND RESTORATION OF THE CATHEDRAL BASILICA OF MANIZALES
}

\author{
OMAR D. CARDONA ${ }^{1 *}$ AND SAMUEL D. PRIETO (1949-2016) ${ }^{2}$ \\ ${ }^{1}$ Instituto de Estudios Ambientales (IDEA) \\ Universidad Nacional de Colombia \\ Sede Manizales, Colombia \\ e-mail: odcardonaa@unal.edu.co, http://idea.manizales.unal.edu.co, (*corresponding author) \\ ${ }^{2}$ INGENIAR: Risk Intelligence \\ CAD/CAE Ltda. \\ Carrera 19A 84-14, Bogotá, D.C, Colombia \\ web page: http://www.ingeniar-risk.com
}

Keywords: Historical Building, Vulnerability Assessment, Seismic Retrofitting.

\begin{abstract}
The Cathedral Basilica of Manizales is one of the most representative buildings of the so-called "republican architecture", boosted in a remarkable and singular way after the fires of the 1920s in the city of Manizales, Colombia. Its "eclectic neo-gothic" design was made in Paris, after the fire that destroyed the city's previous cathedral in 1926. This masterpiece of Colombian architecture turned ninety years old in 2018 after the first stone was laid in 1928. Its construction was carried out in "reinforced cement"; few decades after the appearance of reinforced concrete. During its ninety years, the cathedral suffered earthquakes of high intensity, in 1938, 1962 and 1979, which have significantly compromised its structure. Earthquakeresistant rehabilitation studies to preserve the temple, declared a National Monument in 1984, were promoted at the end of the 1990s. They were the diagnosis of the structural conditions of seismic vulnerability and how it could be provided a greater capacity of response in terms of stiffness, resistance and dissipation of energy, as well as the diagnosis of the state and pathology of the materials. This included geotechnical studies of seismic amplification, dynamic behavior using environmental vibrations, $3 D$ virtual modeling, and structural analysis, even with finite elements. For the reinforcement, the intervention of the base of the central spire was proposed, the control of the stability of the four corner spires, the construction of new structural walls joined in strategic points; founded in caissons and connected to each other in the upper level to guarantee the action of the diaphragm and a better seismic behavior of the structure. The interventions to improve the seismic resistance of the cathedral were carried out between 2002 and 2004. The treatment and protection of the concrete and other necessary interventions of its sculptures and images were carried out between 2016 and 2017. The objective of this document is to describe how a new generation of local specialists have studied and proposed, for this temple of 113 meters high, its seismic reinforcement, the treatment of its materials and other necessary protection interventions, in accordance with the state of the art of earthquake engineering, design, and construction of RC structures and the protection of historical heritage.
\end{abstract}




\section{INTRODUCTION}

The Cathedral Basilica of Manizales has endured earthquakes of significant intensity, in 1938, 1961, 1962 and 1979 that they have seriously compromised their structure. The earthquake of 1962 produced partial destruction and the collapse of the northwest tower. In 1979, although the cathedral had been repaired, it suffered serious damage to its main structural walls. The temple originally thought as invulnerable was not and demanded to make new structural reinforcements and interventions that were projected twenty years later (1999) and that have been carried out during the two following decades of the new millennium. The departmental government, with the support of the national government, promoted the accomplishing of these earthquake-resistant rehabilitation studies to preserve the monument. Taking into account similar works carried out in other Latin American countries, such as the intervention of the Cathedral of Mexico City or the experience with churches from Antigua, Guatemala, the objective of this work is to illustrate in synthesis the studies and interventions carried out in the Cathedral Basilica of Manizales, Colombia, between 1979 and 2019.

\section{AN EMBLEM OF LOCAL SEISMIC CULTURE}

The Cathedral Basilica of Our Lady of the Rosary of Manizales, a temple declared a National Monument in 1984, today of national public interest, is the symbol of a culture: that of the coffee landscape. Its history represents the evolution and innovation of a technique, of science and a culture, immersed in a context characterized by disasters and risk in the face of
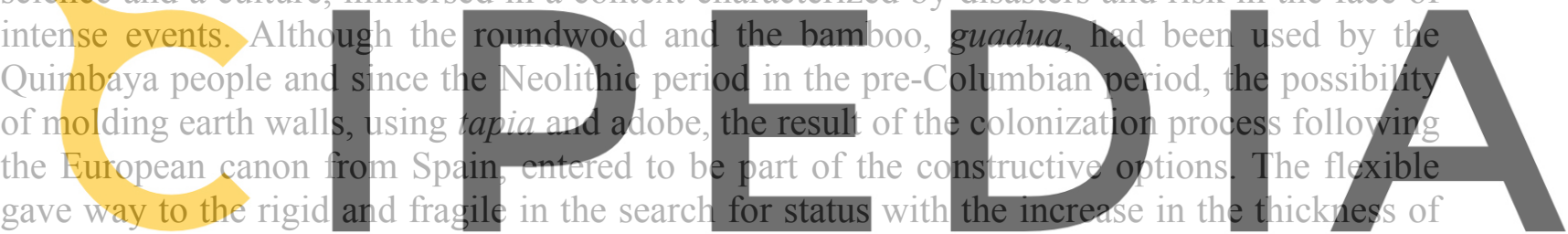

the walls. Thus, between 1854 and 1869 a temple of trodden tapia was built that replaced the

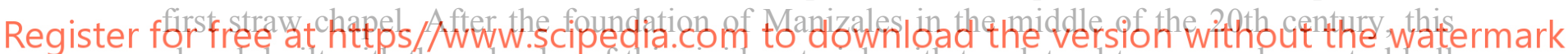
church built with the splendor of this rigid material, with two lateral towers and a central bell

tower, meant the advent of a new but fragile constructive paradigm in the face of earthquakes.

In 1875 the strong earthquake that destroyed Cucuta, another city in the Northeast, also had effects in the coffee region of Colombia. The church cracked importantly, as did other tapia and adobe houses that had been built with the same technique. Subsequently, these damages were increased because of the earthquakes that occurred in 1878, 1884 and 1885. The temple of tapia and adobe was repaired several times, but these last earthquakes severely affected its façade. As a result of the observation and awareness of the inhabitants of the region of the possible consequences due to the earthquakes on the tapia and adobe buildings, the community not only made the decision to demolish the temple but to explore new combinations and constructive techniques more appropriate for the city which they called the "tremors architectural style".

The demolition of the temple of trodden tapia was not an isolated solution to the problem of seismic vulnerability. Noting the rediscovery of the earthquake-resistant empirical techniques of the "tremors architectural style" of the houses from the coffee farms and from the urban center, Mariano Santamaría, Bogota architect, proposed a new design for the church that would take advantage of the "bahareque" from the region. Wood and guadua would adopt the forms of a 
temple that would adapt to the natural peculiarities of this new landscape and its construction was carried out between 1888 and 1897. In the 1920s the novel but precarious electrical network was the cause of they will present short circuits and fires. The fire of 1925 meant the destruction of the city center; tens of blocks were destroyed. The flexible bahareque fell into disrepute because of its vulnerability to fire. In 1926, the wooden Cathedral and two more blocks, which had not been previously affected, suffered the action of a new fire, thus completing a disaster scenario no longer caused by the force of nature. This situation made it necessary to rethink the risk and its different causes and the possibility of exploring new alternatives based on the introduction into the world of the recent Portland cement at that time. In the midst of the controversy about the level of protection against earthquakes and fire, finally, the cemented bahareque replaced the old bahareque and definitively banished the tapia and adobe of the city. The cultural landscape of the rural bahareque evolved into a unique and modern urban bahareque, the result of adaptation and a peculiar awareness of risk in Manizales. Under the name of reinforced cement at that time, concrete technology also became an attractive innovation and an apparent and legitimate alternative for the construction of the new Manizales Cathedral, which should be in principle immune to fires and earthquakes. Angelo Papio \& Jean Carlo Bonarda, Italian engineers resident of Manizales at that time, who would be the builders of the new temple, described the construction system proposed by the French architect Julien Auguste Polti, who won the international competition in Paris for the new Cathedral of Manizales, as follows: "The type of construction we use is the monolithic of reinforced cement throughout its structure and the one that offers absolute guarantees of resistance and fire. This system is adopted in countries where earth into play in the resistance construction suits Mani Cathedral of Manizales, which developed with the curious evolution

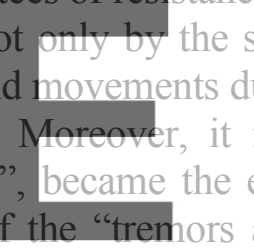

"Republican"

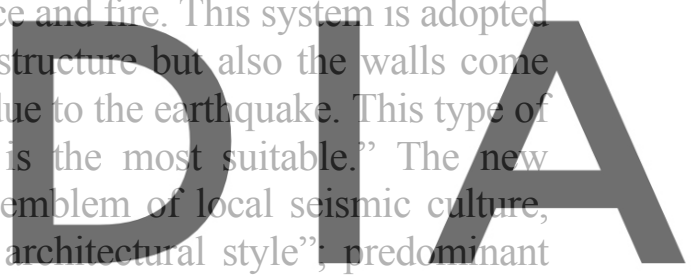

Architecture. The new Cathedral,

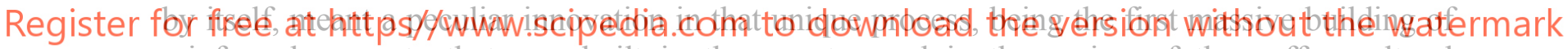
reinforced concrete that was built in the country and in the region of the coffee cultural landscape; declared as World Heritage by UNESCO in 2011

\section{DIAGNOSIS AND DESIGN OF INTERVENTIONS}

The new Cathedral of Manizales, of "neo-Gothic eclectic style" in reinforced concrete, was completed in 1939. It suffered its first earthquake in 1938 when its central spire had not yet been built. Subsequently, during the following decades until the end of the 20th century, its structure suffered the action of several earthquakes that significantly affected it. Although reinforcements, repairs were made and the tower that had collapsed in 1962 was rebuilt, it was early concluded that its conservation depended on the degree of earthquake-resistant protection that could be provided, as a result of a study and a preventive and careful intervention that preserved the monument to the future. The earthquakes of 1962 and 1979 had caused serious damage, his condition was critical, and his permanence depended on the correct interventions being carried out in the shortest possible time. Even a moderate earthquake, such as those that occur with some frequency in the region, was known to compromise the partial or total stability of the monument. For this reason, at the request of the Government of Caldas in the mid-1990s 
and with the support of the Subdirectorate of Monuments of the National Road Institute, today the Directorate of Heritage of the Ministry of Culture, between 1997 and 1999 were carried out studies for the earthquake-resistant rehabilitation of the Cathedral, in order to protect this National Monument. These studies were conducted by a large group of experts [1], according to the state of the art, with the aim of make a detailed diagnosis of the conditions of structural seismic vulnerability and the way in which the monument could be given greater capacity in terms of rigidity, resistance and dissipation of energy to face the seismic demand.

For this purpose, it was based on the realization of a detailed survey and virtual construction of the model of the Cathedral, in order to verify the original plans of Polti, several of which had been restored by the Coffee Cultural Fund (see Figure 1). The plans offered invaluable information for the geometric survey stage, although the information included there did not correspond exactly with the real dimensions of the building. The virtual model was the basis for a three-dimensional discretizing of the temple and analyzing its structural behavior using finite element-based computer programs (e.g. ANSYS, SAP, PDCOMP) (see Figure 2).

The ANSYS program was used to define the structure geometry. In the finite element model, two types of elements were used: Type Beam 4- (elastic beam) and Type Shell 63- (elastic shell). For the construction of the model, it was necessary to use 6437 nodes, 8738 shell-type elements, and 108 beam type elements. For the dynamic analysis, an Eigenvectors analysis was used for the first 10 modes of vibration of the structure. The period of vibration for the fundamental mode was $0.90 \mathrm{sec}$. and for the second and third mode $0.54 \mathrm{sec}$. and $0.36 \mathrm{sec}$ respectively. Using the SAP2000 NL Push, a pushover analysis was carried out, which allowed verifying the capacity of the structure. After and the local seismic performed, one for each of the other strata were estinat cyclic triaxial tests were-perform
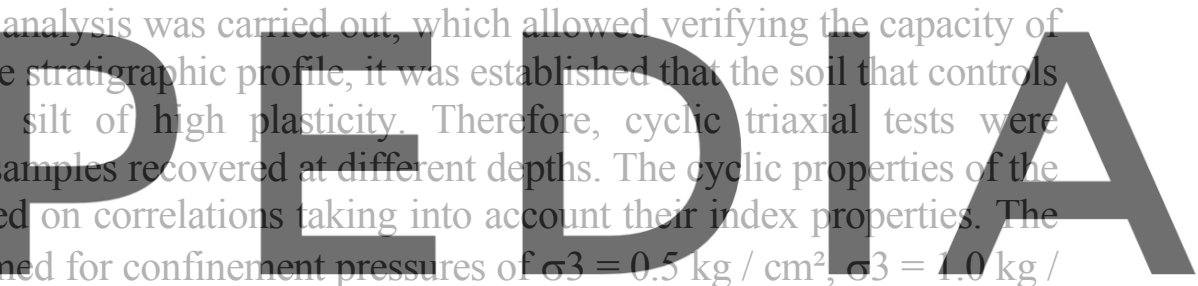

$\mathrm{cm}^{2}$ and $\sigma 3=1.5 \mathrm{~kg} / \mathrm{cm}^{2}$. The observed behavior of the soil corresponds to that of relatively rigid

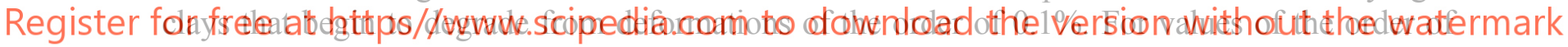
$0.5 \%$ they have already lost up to 50\% of their stiffness. The values of Go varied between 60 and $130 \mathrm{~kg} / \mathrm{cm}^{2}$ depending on the confinement pressure which, in this case, varied between 0.5 and $1.5 \mathrm{~kg} / \mathrm{cm}^{2}$. The damping coefficient with respect to the critic remained at small values until deformations of the order of $0.1 \%$ and only from this value were considerable values achieved until reaching values between $12 \%$ and $23 \%$ for deformations close to $1 \%$.

Taking into account the dynamic properties of the soils, feasible accelerograms and the seismic response spectra for different periods of vibration at the site, the dynamic response of the structure was modeled and evaluated, considering the characteristics and condition of the materials in terms of its resistance and pathology, for which it was necessary to take a large number of samples. This allowed evaluating the structural seismic vulnerability and to design the seismic-resistant reinforcement in such a way that the benefit that these reinforcements would have on the structure could be verified and without generating excessive invasive interventions and preserving the authenticity of the temple.

Initially, with the use of a model of elastic behavior and the definition of a pattern of cracking and fissures simulated by previous earthquakes, obtained from the analysis with environmental vibrations, the inelastic behavior of the structure was assessed. This type of study allowed determining the main deficiencies and weaknesses of the temple to face earthquakes. 

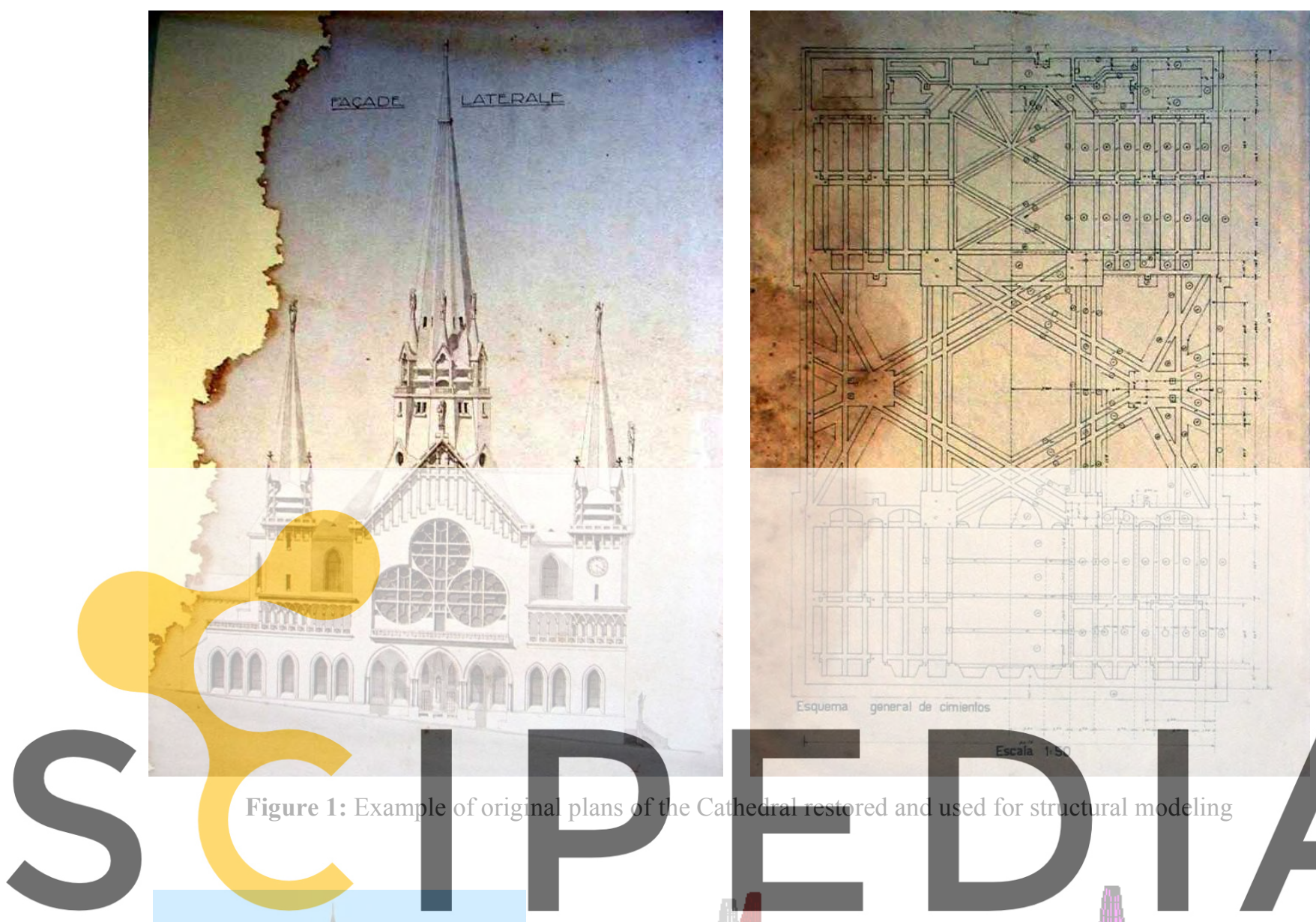

Register for free at https//www.scipedia.com to download the version without the watermark
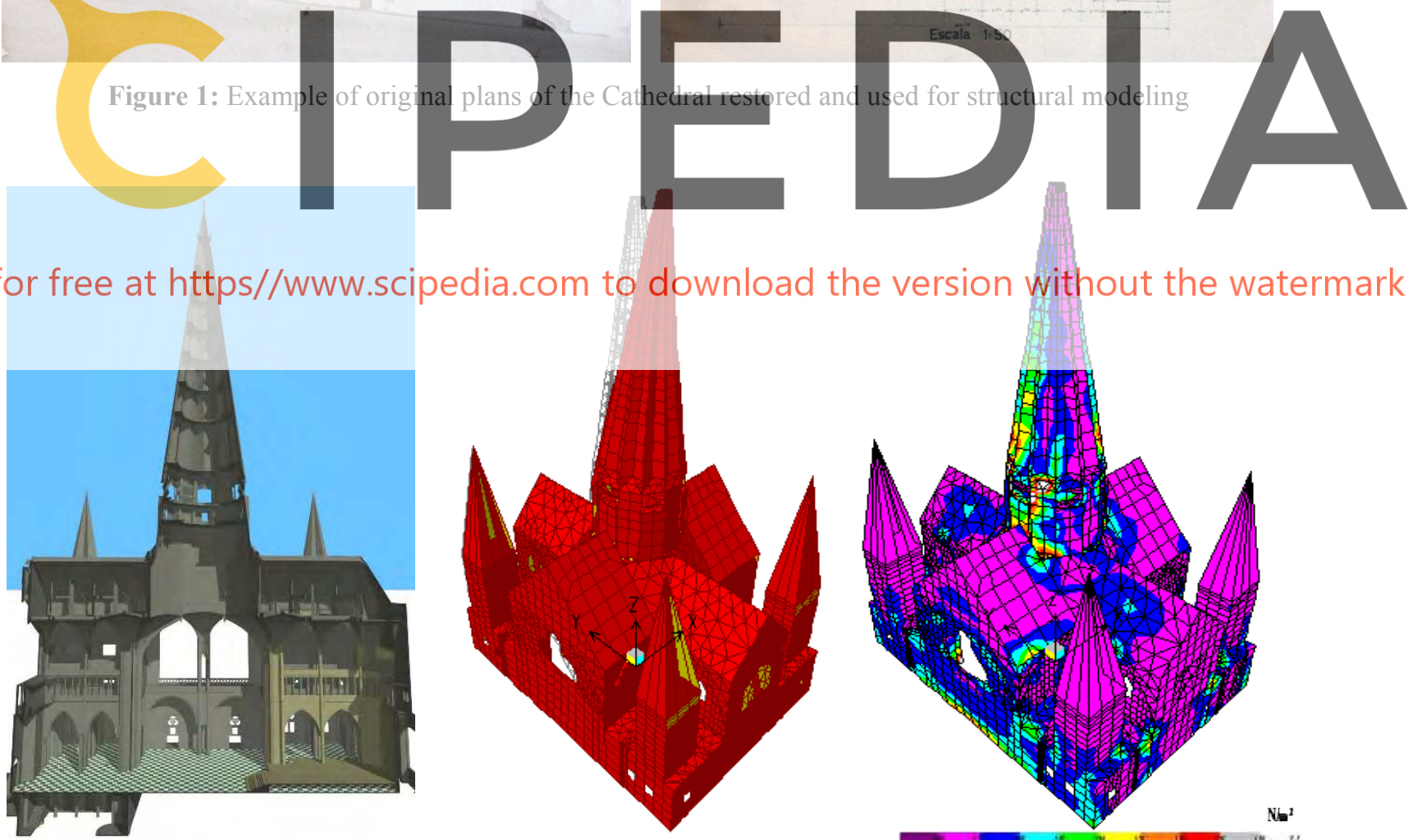

Figure 2: The virtual model was the basis for a three-dimensional fine-element discretizing of the structure 
Efforts could be determined throughout the structure and therefore at critical sites or that could be insufficient to address the most severe seismic actions, a soil-structure interaction analysis was carried out to estimate how the period of vibration of the building and how its structural behavior could relax. The results of these studies indicated that the walls of the Cathedral had cracked in previous earthquakes because they acted in practice in an uncoupled manner. The cracks had arisen precisely because there was no capacity in the walls of the structure to move monolithically in a single set. Most of the cracks and fissures had occurred because of their insufficiency to withstand shear force. On the other hand, since the foundation was a system of joists, some of which are not very rigid due to their height reduction, this would allow, in addition to the seismic action, that the walls would rotate due to lack of embedment. This kind of situation, very unfavorable, explained the decoupling of the walls and their cracks and would have to be corrected. For this reason, it was concluded that it was essential to strengthen the capacity of the existing walls with competent structural elements that would improve the strength and the energy dissipation capacity of the structure and that a new foundation would be carried out that would guarantee its proper embedding in the base.

It was also detected that the central spire induced remarkable efforts at its base when it vibrated at the action of an earthquake. Since near its base where the folded plate that forms the tower was supported in a group of pillars whose reinforcement was insufficient to absorb tension stresses, it was considered that this area was critical and would have to be reinforced. Finally, it could be ratified that the towers or corner spires that had been reinforced after the 1962 earthquake with possibility of instability pertinent to carry out anchorage.

\section{EARTHQUAKE RESISTANT STRUCTURAL REINFORCEMENT}

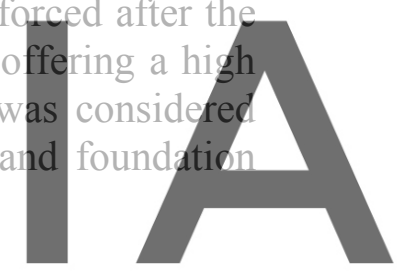

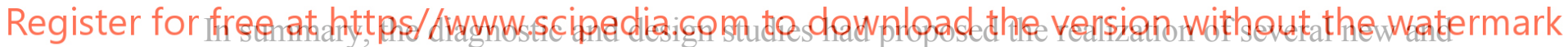
attached structural walls at strategic points to improve the seismic response and the overall behavior of the structure, the intervention of the central spire base and the control of the stability of the four corner spires. At the beginning of the 2000s, the Foundation "Amor por la Catedral Basílica de Manizales" was established, resources were obtained from citizens, the municipality, and the national territorial finance agency, FINDETER. With unique technical coordination, between June 2002 and August 2004, the proposed earthquake-resistant reinforcement works were carried out by direct administration of said Foundation and through several contractors [2].

For a better behavior before the lateral loads it had been established that it was necessary to reinforce the structure by means of eight new orthogonal structural walls located in the periphery; in the places considered of greater efficiency for structural effects and where they will not cause major changes in the original architecture of the building. These walls could replace existing walls, however, due to the difficulties that this meant for the construction, it was established that said walls should be built attached by means of anchors to the existing walls (see Figure 3 ). This situation, although minorly modifying the façade, was preferable since the vertical loads were still transferred to the foundation by the existing walls. On the other hand, great difficulties and risks were avoided in the construction process, otherwise it would have been necessary to temporarily 
hold large vertical loads as well as the thrusts of the arches that converge there. These new walls had to have edge elements capable of supporting the moments that would be generated in case of an earthquake and that must reach the foundation based on a new high foundation beam, located below the existing foundation, which in turn should be built supported by caissons that will guarantee the embedding or non-rotation of the new walls; issue that was very difficult to carry out but that was necessary (see Figure 4). These new structural walls had beams at different levels and at the top to ensure that they could be connected by a network of new beams that formed a ring at the level of the diaphragm between levels 24 and 27 meters and with the purpose to provide an ideal system to absorb tension stresses when the structure would be moved by an earthquake. These beams were built using steel plates attached and bolted to the high ribs of the vaults that reach the heads of the walls and that connect to the dome under the central spire, achieving the connection and transmission of forces and the effect of diaphragm with the new structural walls in the form of L and that finally they were built internally and externally attached to the walls of the structure (see Figure 5).

The central spire was intervened at its base by means of six reinforcing walls attached to the folded plate that forms the tower. In this way, the capacity of the structure at the base of the spire to withstand tension stresses when it becomes subject to lateral forces caused by earthquakes was improved. These walls were built internally so that from the outside it is not possible to see them and because of a recent earthquake they have already presented cracks, which illustrates that they have already been working (see Figure 6). In addition, this internal work was used in the central spire to make a new internal metallic helical staircase that allows people to climb up to the tip of the central spire where Finally, in order to eight special rods of 7.5 structure of each towar at the 11.20 meter levd with a new b which they must be anchored (see Figure 7).
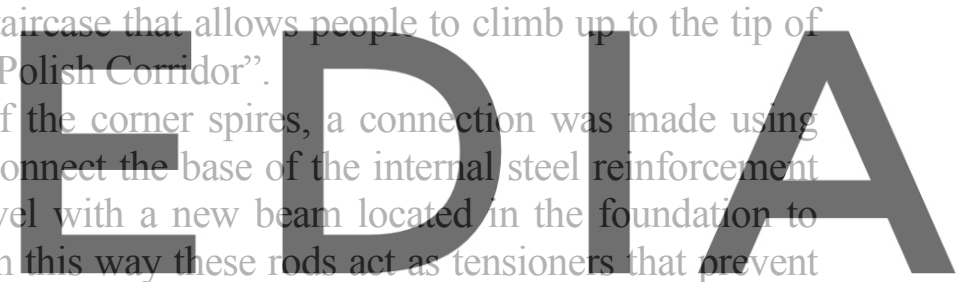

the turn of the towers in case of a strong earthquake

Register for free at https//www.scipedia.com to download the version without the watermark 4 TREATMENT AND PROTECTION OF CONCRETE

The treatment of the concrete's state of the Cathedral has been, together with other general maintenance activities, the last interventions that have been made to the monument. The treatment and protection of concrete was one of the interventions that, with special emphasis, should be carried out accordingly with the recommendations of the comprehensive diagnostic and structural reinforcement project in 2000 [1]. At that time when the evaluation of the state of the materials and the pathology of the concrete was made, it was concluded that there was already a significant advance in the carbonation of the concrete and that it would surely be aggravated if it was allowed to pass a long time without intervening. This was ratified in a more detailed study that was carried out in 2013 [3] and that resulted in the urgent need to intervene "the skin" of the Cathedral and also carry out another series of relevant interventions related to the repair of decorative elements and cornices, the construction of a new and adequate system of downspouts, the reconstruction of the sewer system and the intervention of the sculptural works and images of the facades and towers [4]. This maintenance, which must actually be a periodic activity, was carried out in 2018, following the technical and protection recommendations of the Heritage Directorate of the Ministry of Culture. 

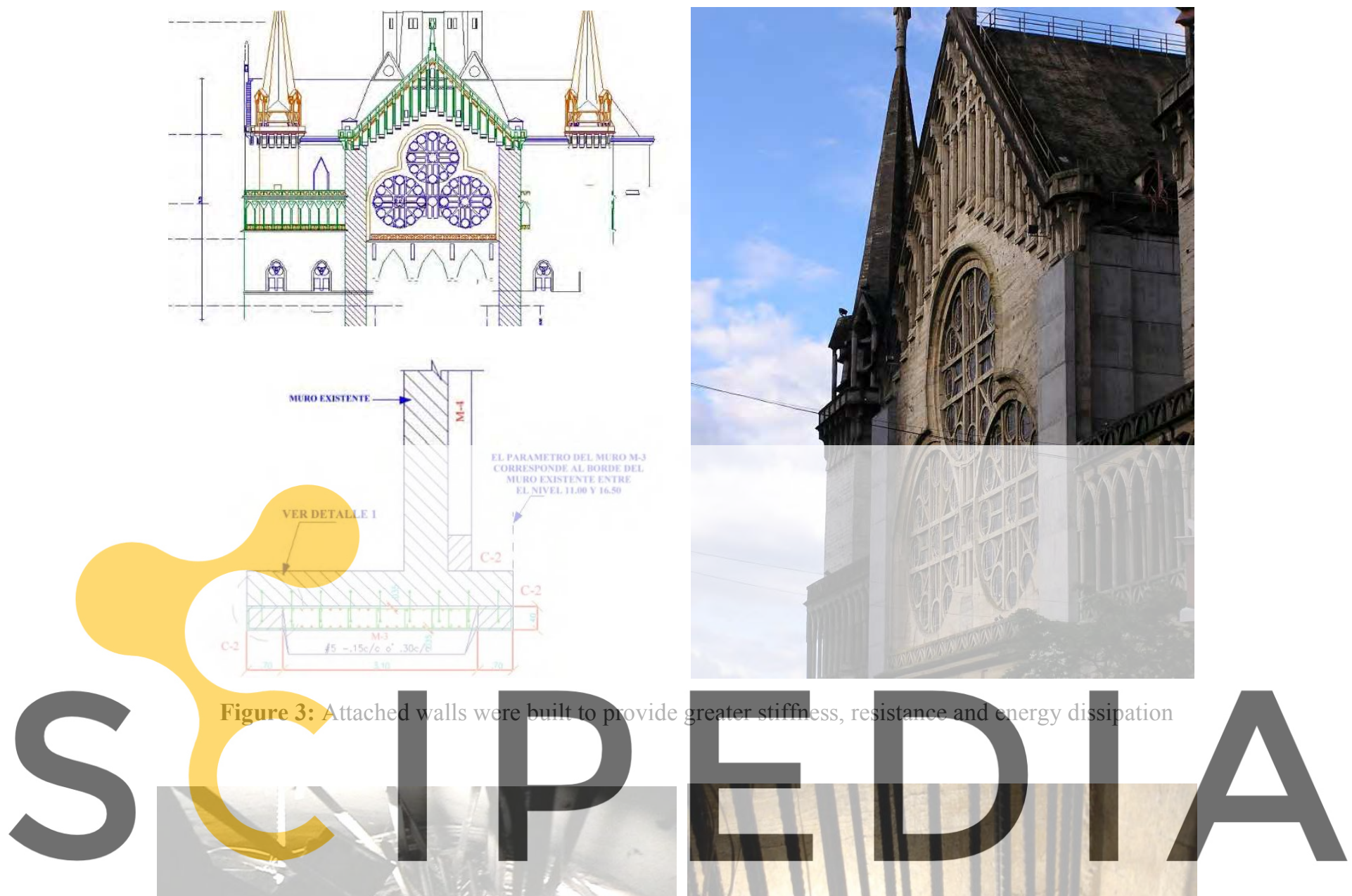

Register for free at https//www.scipedia.com to download the version without the watermark
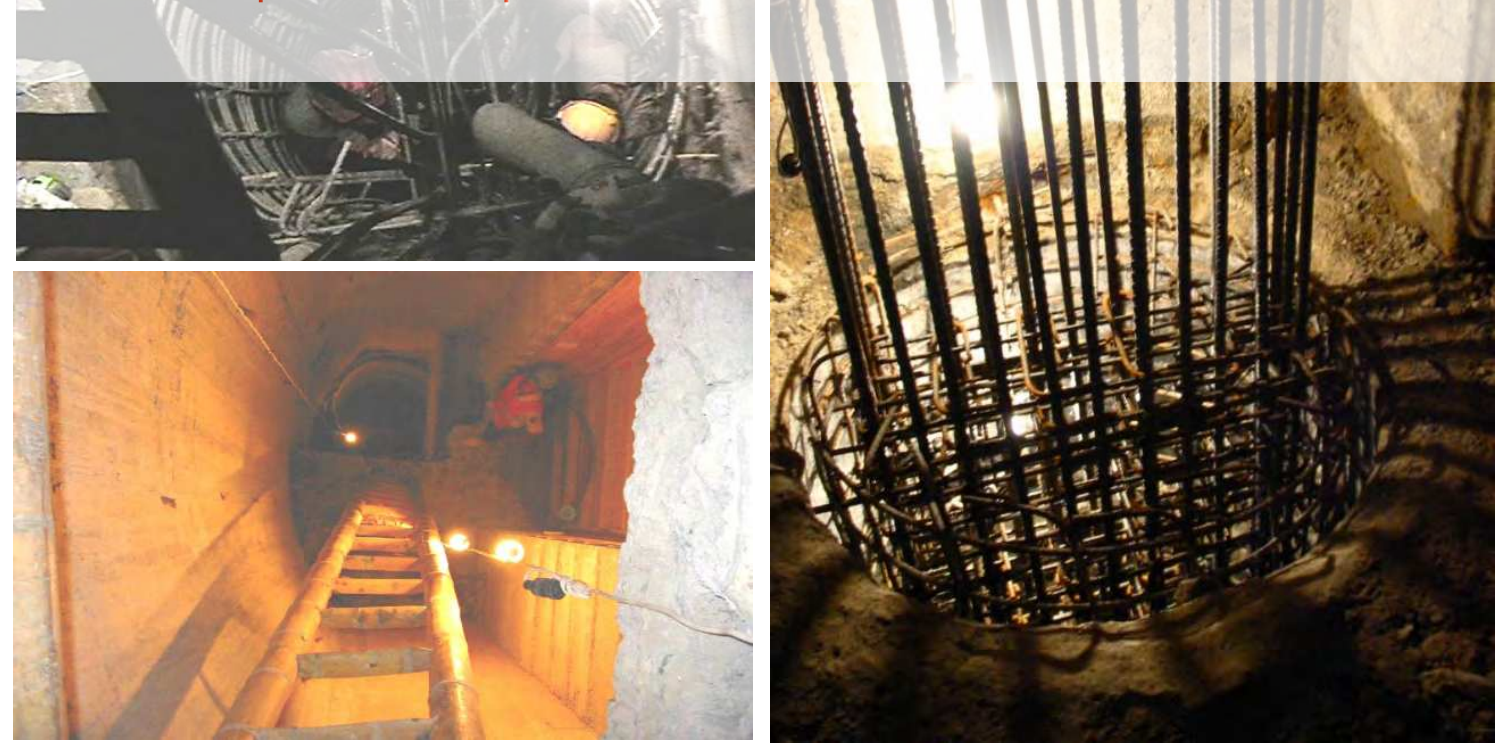

Figure 4: Foundation with caissons to prevent rotation at the base of the structural walls 


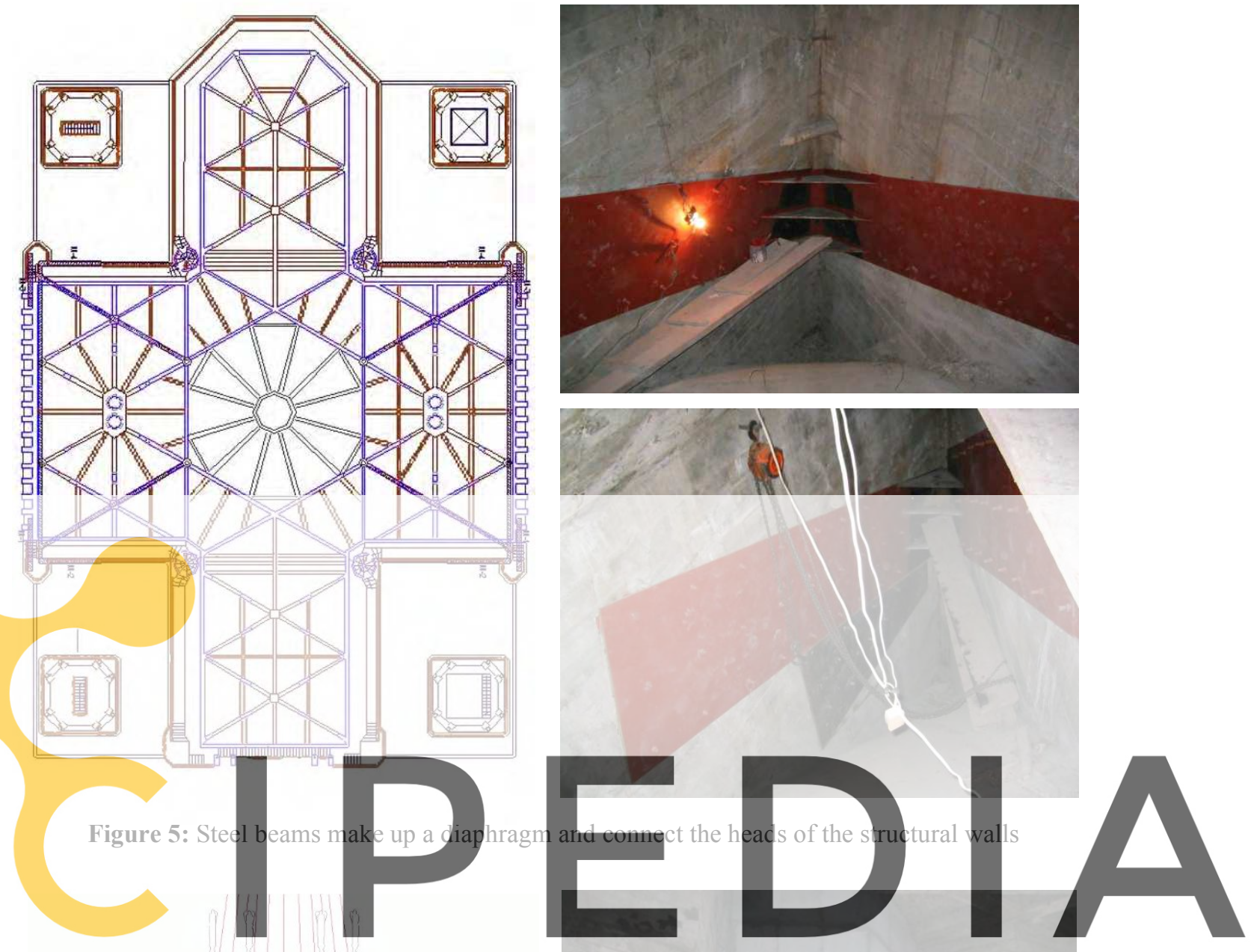

Register for free at https//www.scipedia.com to download the version without the watermark
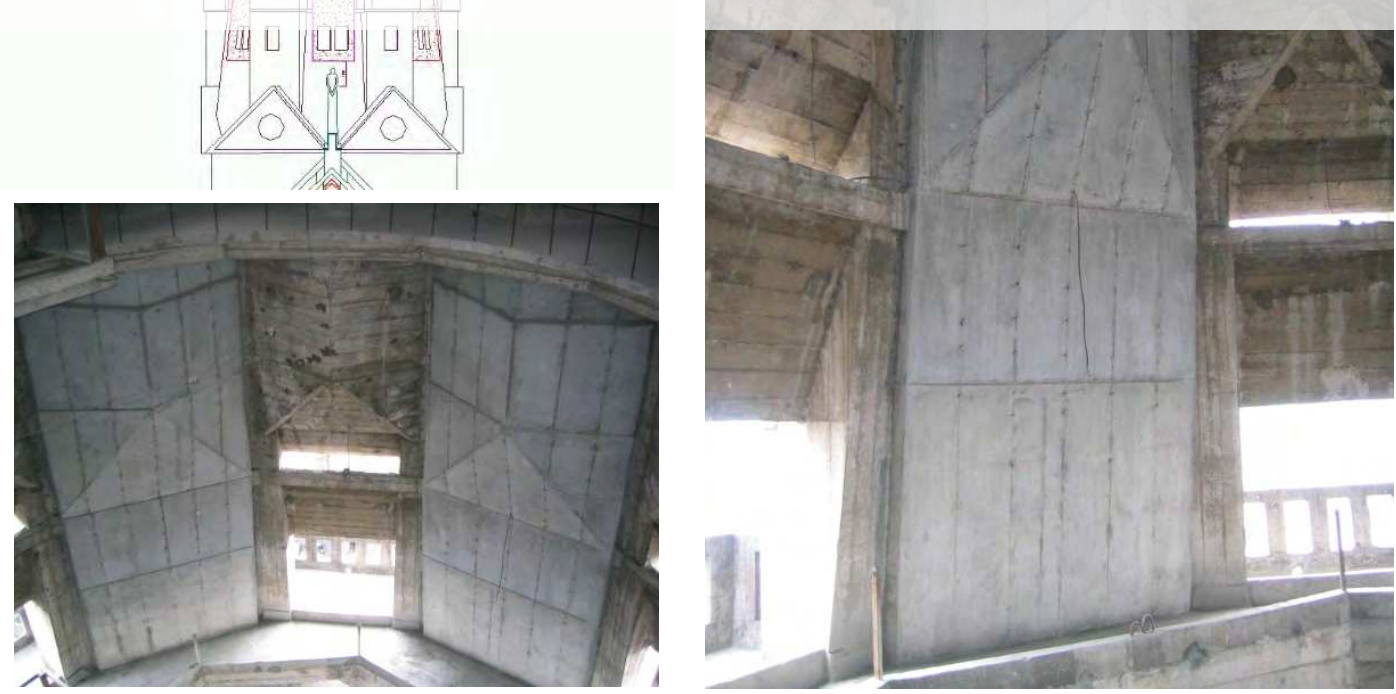

Figure 6: Internally attached reinforcing walls were constructed at the base of the central spire 
Two phases of this maintenance were planned. In its first phase, the most urgent activities were included. On the one hand, the removal of mortars from terraces, canals, and walkways, which were replaced with sloping cement to improve adhesion, waterproofing and mechanical resistance to traction and bending. This process was complemented by the application of a product that minimized cracking and where necessary additional reinforcements were made with welded mesh. The slopes were oriented towards the grilles that were projected according to the new hydraulic installations that were projected and made. Also, the washing and disinfection of the façade were carried out by applying a corrosion inhibitor and a water repellent was applied. A type of biocide with properly diluted benzalkonium chloride was applied and for the minimum recommended time, which was also facilitated with the use of plastic bristle brushes to improve the action of this product in the different layers of the dirt layers, particles pollutants, and biofilm that had formed over the years. Then the cleaning was carried out with a pressure washer with a pressure less than $750 \mathrm{psi}$, with a fan jet and more than $30 \mathrm{~cm}$ away between the nozzle and the concrete to avoid damage to the concrete. Once the surface dried, for which at least three sunny days were required, the corrosion inhibitor or passivator was applied to the reinforced concrete at the sites of greatest relevance of the bases and towers. This process had setbacks due to changes in color in the concrete that had to be corrected with abundant rinses and due to the need for the surface to dry, which was not facilitated due to persistent rains. Additionally, due to the lack of water pressure in the highest parts of the temple, a system that kept the pressure constant had to be developed. The final stage was the application of the water repellent in order to repel water, prevent corrosion and achieve a coating that prevents the new appearance of moss. To the extent

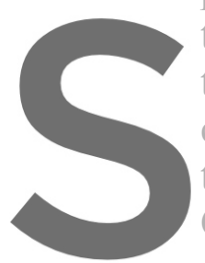
that this product was this type of repairs, completion of this work the temple. Figure 8 Cathedral. The dark appearance suffered for many years was eliminated.
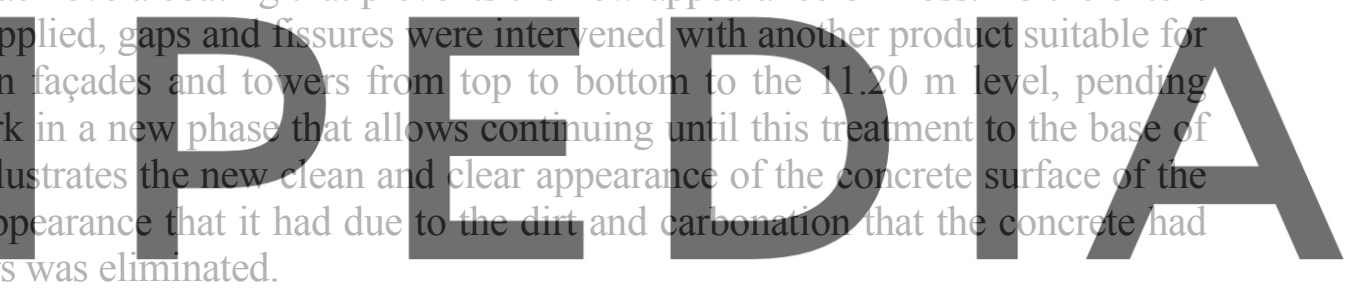

On the other hand, this was also the opportunity to repair the cornices and decorative elements of

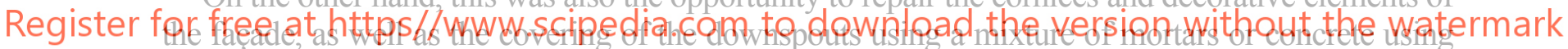

proportions of dyes. Multiple trial and error tests were performed in order to simulate the original color of the concrete of the Cathedral. Sixty-five samples and cores were taken to verify the carbonation state of the concrete and dust extraction tests to verify from a chemical point of view in the laboratory the condition of the concrete paste. Cleaning the interior vaults of bird droppings, garbage, fragments and even wood that were from the construction was carried out, and synthetic meshes were also placed to prevent birds from entering these sites as they did before. To improve water management that was very precarious, an appropriate system of siphons, grilles, and downspouts was constructed, and the sewer of the surrounding streets was replaced due to its very poor condition when its respective revision was made. Finally, as a result of the strong deterioration, twenty-two sculptures of the five spires of the temple were changed, replacing them with new ones or repairing them, which allowed preserving the original icons of the Cathedral. These images were made using weather-resistant epoxy resin and the existing cross in the central spire was replaced by the one called the Levitating Christ, which required not only careful technical work on materials, construction processes, platforms and scaffolding in height, but the skill and artistic ability of a renowned sculptor of the city. The concrete sculptures that are located on the roofs were also maintained, as well as the sculptures of the guardian angels located at the base of the central spire. The concrete of these images was washed, disinfected and hydrofuge was applied like in the structure. 


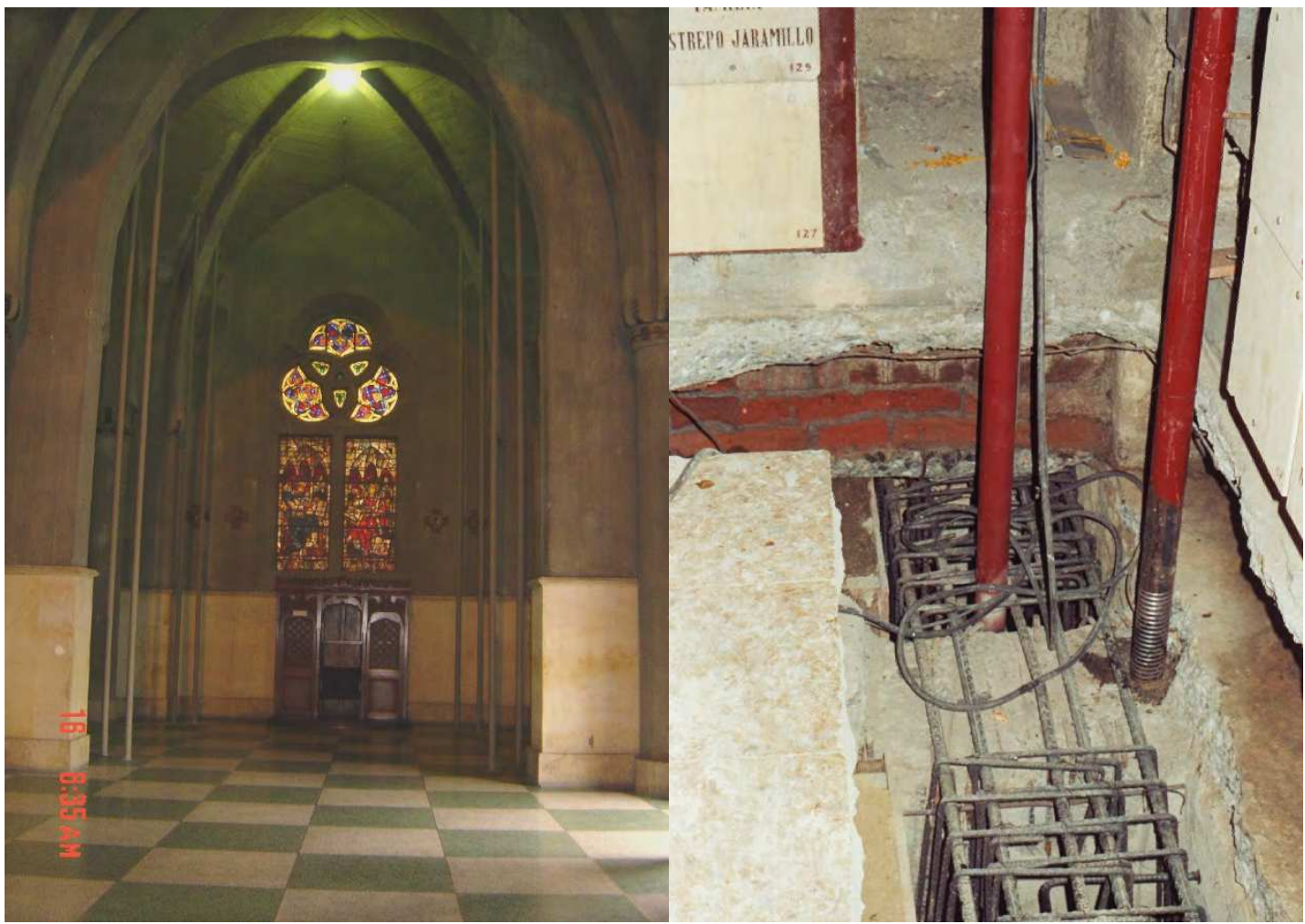

Figure 7: Eight rods or tensioners provide stability to corner spires in case of an earthquake

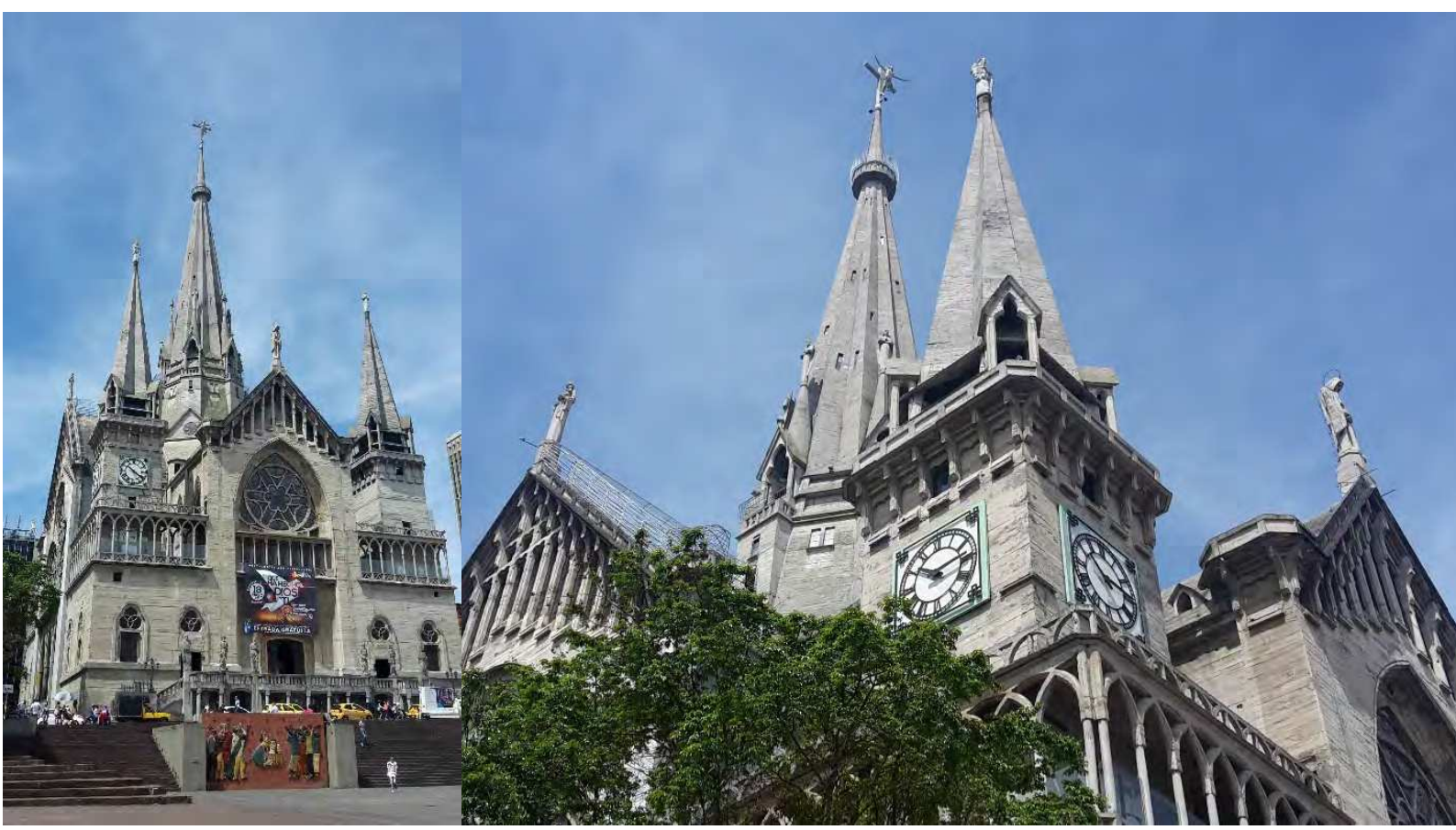

Figure 8: The current appearance of the Cathedral after washing and concrete treatment and protection 


\section{CONCLUSIONS}

A summary description of the interventions of the structure, the conditions of the concrete, the decorative elements and the sculptures, which have been made to the Cathedral of Manizales, have been presented. These interventions were the result of the Integral Project of Diagnosis and Design of the Structural Reinforcement, which was disclosed in 2000 [5]. The reports indicated the works of structural reinforcement and protection of the monument that should be carried out to protect this masterpiece of Colombian architecture, after the study that was carried out on the state of the materials, modeling, and evaluation of the response seismic, vulnerability diagnosis and structural reinforcement design. The earthquake-resistant intervention was carried out between 2002 and 2004 and the treatment of concrete and other necessary interventions were carried out between 2016 and 2017 [6]. This illustrates the effort that is necessary in these cases to obtain the necessary economic and professional resources to carry out the protection works of a heritage monument. Although the second phase of maintenance is still needed, which must actually be permanent in such a structure, it can be concluded that the decision of a number of people committed to these efforts, with their expertise and management, have been the ingredient fundamental to ensure that this monument has been protected and that it is preserved for posterity, with the aim of continuing to be an emblematic masterpiece of the local seismic culture of the city of Manizales.

Acknowledgements. These works were supported by Departamento de Caldas, Subdirección de Monumentos INVIAS, Fundación Amor por la Catedral Basílica de Manizales, Municipio de Manizales, Findeter, Arquidiócesis de Manizales, Ministerio de Cultura, Dirección de Patrimonio.

\section{REFERENCES}

[1] Cardona O.D., García-Reyes, L.E., Aycardi, L.G., and Esguerra, J.E., Ocampo, J.G., Zambrano, J., Arcila, C.A., Correal, J.F., Jaramillo, J.D., Estrata, W., Sarmiento, J.M., Prieto, S.D. Proyecto Integral de Diagnóstico y Diseño del Reforzamiento Estructural, 1997-1999, Departamento de Caldas, Subdirección de Monumentos, INVIAS, (1999). Manizales.

[2] Prieto, S.D., Estrada, J., Botero, J.B. Construcción del Reforzamiento Estructural Sismorresistente, 2002-2004, Aquaterra, S.A., Caseven, Ltda., Fundación Amor por la Catedral Basílica de Manizales, Municipio de Manizales, Findeter. (2004). Manizales.

[3] Arcila, C.A. Evaluación detallada de la patología del concreto. (2013). Manizales.

[4] Londoño, J.I., Muñoz, J.F., Vallejo, L.G., Estrada, H., Mejía, E., Bermúdez, J.M., Cardenas, D.C., Flórez J.F., Serpa, E., Parra, C.R., Reparación y Mantenimiento, Conservación y Restitución de Esculturas, 2016-2017. Arquidiócesis de Manizales, Diprecón, Ministerio de Cultura - Dirección de Patrimonio, (2017). Manizales.

[5] Cardona, O.D. Protegiendo nuestro patrimonio. Estudios de vulnerabilidad y reforzamiento estructural: Catedral Basílica de Manizales Noticreto (2000) 55:59-65.

[6] Cardona, O.D. and Prieto. S.D. Protección de un monumento emblemático. Refuerzo, rehabilitación y restauración de la Catedral de Manizales Noticreto (2019) 154:10-15. 